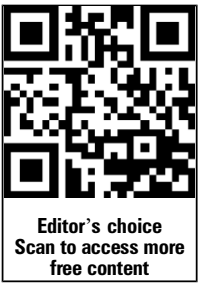

- Additional material is published online only. To view please visit the journal online (http://dx.doi.org/10.1136/ thoraxjnl-2012-202875)

${ }^{1}$ Respiratory Department, Sir Charles Gairdner Hospital, Perth, Western Australia, Australia

${ }^{2}$ Division of Surgery and Interventional Sciences, University College London, London, UK

${ }^{3}$ Academic Respiratory Unit, School of Clinical Sciences, University of Bristol, Bristol, UK

\section{Correspondence to} Dr Fraser John H Brims, Respiratory Department, B block, Sir Charles Gairdner Hospital, Hospital Avenue, Nedlands, Perth, WA 6009, Australia;

Fraser.Brims@health.wa.gov.au

Received 15 October 2012 Revised 11 February 2013

Accepted 24 February 2013 Published Online First 20 March 2013

\title{
Ambulatory treatment in the management of pneumothorax: a systematic review of the literature
}

\author{
Fraser John H Brims, ${ }^{1,2}$ Nick A Maskell ${ }^{3}$
}

\begin{abstract}
Introduction Spontaneous pneumothorax (SP) is broken down into primary (PSP: no known underlying lung disease), secondary (SSP: known lung disease) and from trauma or iatrogenic pneumothorax (IP). Current treatments include a conservative approach, needle aspiration, chest drain, suction and surgery. A Heimlich valve $(\mathrm{HV})$ is a lightweight one-way valve designed for the ambulatory treatment of pneumothorax (with an intercostal catheter).
\end{abstract}

Methods We performed a systematic review across nine electronic databases for studies reporting the use of HV for adults with pneumothorax. Randomised controlled trials $(R C T)$, case control studies and case series were included, unrestricted by year of publication. Measures of interest included the use only of a HV to manage SP or IP, (ie, avoidance of further procedures), successful treatment as outpatient (OP) and complications.

Results Eighteen studies were included reporting on the use of HV in 1235 patients, 992 cases of SP (of which 413 were reported as PSP) and 243 IP. The overall quality of the reports was moderate to poor with high risk of bias. Success with HV alone was 1060/1235 (85.8\%) and treatment as OP successful in 761/977 (77.9\%). Serious complications are rare. Long-term outcomes are comparable with current treatments.

Conclusions High-quality data to support the use of HV for ambulatory treatment of pneumothorax is sparse. The use of HV in such circumstances may have benefits for patient comfort, mobility and avoidance of hospital admission, with comparable outcomes to current practice. There is urgent need for a carefully designed RCT to answer his question.

\section{INTRODUCTION}

Pneumothorax is defined as the presence of air in the pleural space. ${ }^{1}$ It was first described by Itard in 1803, and treatment with needle aspiration (NA) then described by Bell in $1804 .^{2}$ Spontaneous pneumothorax (SP) is broken down into primary (PSP: no known underlying lung disease), secondary (SSP: known lung disease) and nonspontaneous from trauma or iatrogenic pneumothorax (IP: most commonly from subclavian vein catheterisation and transthoracic biopsy ${ }^{3}$ ). In the USA, the incidence of PSP presenting to hospital is 7.4/100 000 for men and 1.2/100 000 for women per year, and for SSP 6.3/100 000 (men) and $2.0 / 100000$ (women) per year. ${ }^{4}$ In the UK, between 1950 and 1997, the incidence of SP (PSP and SSP combined) in those presenting to hospital was $16.7 / 100000$ for men and 5.8/100 000 for women per year. ${ }^{5}$ When combined with new

\section{Key messages}

What is the key question?

- Controversy exists with the optimal management of pneumothorax, and Heimlich valves (HV) with an intercostal catheter may offer an alternative to current conventional therapy. We performed a systematic review to examine the existing data for effectiveness and safety for the use of HV in spontaneous and iatrogenic pneumothorax.

What is the bottom line?

- Quality reliable data is sparse, but there is enough to suggest that HV for pneumothorax may be effective and safe in the ambulatory treatment of pneumothorax with avoidance of further procedures in the majority of cases.

\section{Why read on?}

- The ambulatory management of pneumothorax is attractive as it is likely to improve comfort and mobility, and reduce or avoid hospital admission, with comparable outcomes to current treatments.

presentations to primary care, the rates rise to 40.7 (men) and 15.6 (women) per 100000 per year. $^{5} \mathrm{SP}$ classically affects men more than women (ratio $2.5: 1)^{5}{ }^{6}$ and those with 'ectomorphic' body habitus. ${ }^{1}$ PSP carries a very low mortality with most cases of death from SP occurring above the age of 55 years, ${ }^{5}$ suggesting that the majority of these cases are likely to have SSP with underlying lung disease. The underlying pathological cause of SP is likely to be the rupture of small bullae or blebs (so-called 'emphysema-like changes') on the pleural surface, which allows egress of air from the lung into the pleural space.

Despite recognition of pneumothorax for more than 200 years, there still remains significant controversy and a wide variation in treatment both nationally and internationally. ${ }^{8-11}$ The poor consensus in recommended management of SP is highlighted by three international guidelines (the American College of Chest Physicians Delphi consensus statement from $2001,{ }^{12}$ the British Thoracic Society guidelines $2010^{8}$ and the Belgian Society of Pulmonology guidelines $2005^{13}$ ) contrasting sharply in many aspects of proposed treatment, and these international bodies do not even agree on a definition of 
size of pneumothorax. Many experts increasingly argue that treatment options for PSP should concentrate more on patientorientated aspects, such as symptoms, rather than chest x-ray (CXR) appearances. ${ }^{9}$ The approach of managing PSP based on clinical and symptomatic criteria as compared with CXR appearance, is currently being examined in a large Australasian randomised controlled trial. ${ }^{14}$ The lack of clear consensus in treatment likely contributes to both the poor adherence to guidelines and wide variations in practice that are observed worldwide.

Conventionally, the recognised treatment options for SP include a conservative approach (ie, observation alone) for small SP, NA of air from the pleural cavity, or placement of an intercostal chest tube (ICT) connected to an underwater seal. ${ }^{8} 12$ Persistent air leak can be managed with the use of an ICT with underwater seal connected to suction (a practice with little evidence base) and, after prolonged air leak, surgery to repair or resect the damaged lung followed often by pleurodesis (the iatrogenic induction of pleural fibrosis) is advocated. ${ }^{8}{ }^{12}$ NA alone has been demonstrated to carry a highly variable success rate of $30-80 \%{ }^{8}$; after NA failure, with current accepted approaches, admission for inpatient treatment is required for persistent pneumothorax.

Ambulatory treatments for some diseases are desirable for healthcare institutions not least for the potential financial implications of inpatient bed-days saved. The treatment of SP, and in particular PSP would lend itself well to outpatient (OP)-orientated management; patients are generally young, with few or no comorbidities, and the condition itself caries a low morbidity and mortality. ${ }^{5}$ This is not a new concept, with reports in the literature dating back to $1973^{15}$ advocating the use of a Heimlich flutter valve (HV: a lightweight one-way valve specifically designed for the ambulatory treatment of pneumothorax ${ }^{16}$ ) attached to an intercostal catheter with patients managed out of hospital. This approach is very attractive to patients as it does not involve connection to a drain bottle, and thus, encourages mobility and ability to more comfortably perform common activities of daily living. 1718

This systematic review was designed to concisely assess the published literature to examine the evidence for the use of Heimlich valves (HVs) in the management of adults with pneumothorax as compared with conventional approaches and, furthermore, to establish if such management can be safely and effectively performed in an OP environment.

\section{METHODS}

We used a systematic review methodology based on the PRISMA $^{19}$ approach and principles. As the authors were aware that high-quality trials data is lacking in this subject field, we specifically allowed consideration of case series within the summation of the literature.

\section{Eligibility criteria}

Studies were considered eligible for inclusion with the following criteria: adult patients with spontaneous (primary and secondary) and IP; interventions consisting of conservative approach, NA, ICT, catheter and HV; comparator with any one of the above; outcome: an assessment of the efficacy or reported success of the treatment modality; randomised controlled trials (RCTs), case control study, case series. Exclusions consisted of the following: letters, editorials and studies examining pneumothorax post-thoracic surgery or traumatic pneumothorax. Studies involving postsurgery cases with a clear delineation of outcomes between SP and surgery cases were permitted.

\section{Sources of information}

The search strategy included several data sources unrestricted by years of publication although the full text of the study must have been in English. The literature search included the following electronic (online) databases: Cochrane Library (including the Cochrane Central Register of Controlled Trials (CENTRAL), Cochrane Databases of Systematic Reviews (CDSR), Database of Abstracts of Reviews of Effects (DARE), Heath Technology Assessment (HTA) database, National Health Service (NHS) Economic Evaluation database (EED)), Medline (through Pubmed interface), Embase, and Web of Science.

Searches were conducted between 5 April and 15 May 2012. We used the following search terms, adapted for each database as appropriate

- (Drainage OR thoracic drainage OR ambulatory care OR catheters OR catheterisation OR aspiration OR needles OR needle OR manual OR simple OR spontaneous (MeSH terms), with HV (all fields)) AND

- (pneumothorax (MeSH term) OR pneumothoraces (all fields)) AND

- (clinical trial OR randomised controlled trial OR comparative study OR evaluation OR case report (publication type)).

In addition to electronic database scrutiny, we hand-searched textbooks and reference lists of included studies and articles. Lead authors and subject experts were contacted to establish any unpublished grey literature. We included any studies fulfilling the above criteria, and then independently screened and assessed each article identifying those potentially relevant. Studies were reviewed in three stages based on the title, abstract, and then full text with consensus sought at each stage of review. Two authors (FJB and NAM) independently performed the literature search and assimilation of suitable reports. The protocol utilised for the study is available in the supplementary material online.

\section{Data collection process}

For selected studies, data were extracted onto an electronic form (Microsoft Excel 2010, Microsoft Corp, USA). Extracted information included: authors, year, geographical area, sample size, nature of pneumothorax (primary, secondary, iatrogenic, mix), intervention type(s), any control/comparator measures, outcomes reported-for each intervention, timescale of assessment, reported complications, study type, assumptions/ simplifications.

\section{Quality—risk of bias in individual studies}

The overall quality of each study was judged independently by the two authors (FJB and NAM) including assessment of study type, internal validity, generalisability, heterogeneity and precision.

For comparative experimental studies we assessed the adequacy of sequence generation, allocation concealment, blinding, completeness of data, outcome reporting and baseline comparability.

\section{Measures of interest}

The primary measure of interest was use only of a HV (with intercostal catheter) to manage the pneumothorax, that is, avoidance of larger ICT and/or surgery; this outcome forms the definition of 'overall success' within the presentation of results.

Additional measures of interest were as follows: where applicable-use of a HV to facilitate only outpatient-based treatment; use of $\mathrm{HV}$ for different types of pneumothorax (PSP/SSP/IP) 
need for surgery; recurrence rate (more than 1 week after treatment); financial assessment/implications; reported complications with 'serious' complication defined by the following: death, life threatening or serious injury, need for hospital admission, or prolonged admission, persistent or significant disability or incapacity. For financial considerations, due to variance in currency and wide difference in dates of studies, a cost ratio was calculated, rather than using original costs reported.

\section{Synthesis of results}

Where possible, estimates of effect were collated across the selected studies. Due to the wide heterogeneity and noncomparative nature of the studies, a simple proportion of each outcome of interest was calculated.

\section{RESULTS}

Eighteen studies from nine countries over a period of four decades reporting on the use of a HV in 1235 patients were eligible for review. Figure 1 presents a flow chart for full breakdown in the identification of suitable studies. This included two RCTs $^{20} 21$ and three prospective series, ${ }^{17} 1822$ the rest were retrospective case series. ${ }^{15}$ 23-34 There were 992 cases of SP (of which 413 were reported as PSP) and 243 IP. Two studies included reports on postsurgical patients, from which the results were clearly separated from SP and IP, allowing inclusion. ${ }^{18} 24$ Table 1 provides a summary of included reports.

\section{Risk of bias assessment}

As all but two of the studies available were case series, the overall quality assessment of the assimilated data was assessed as moderate to poor, with a high risk of bias.

\section{Primary and secondary outcomes}

Data synthesis on outcomes was not possible. The two randomised controlled studies included had different comparators with use of $\mathrm{HV}$ against $\mathrm{NA},{ }^{20}$ and $\mathrm{HV}$ against ICT, ${ }^{21}$ prohibiting further evaluation. Therefore, we provide a narrative synthesis. Table 2 provides a summary of key outcomes. Reported overall success (use of $\mathrm{HV}$ with no further intervention) was $85.8 \%$ (95\% CI 83.7 to 87.7). Thirteen studies describe the use of a $\mathrm{HV}$ in an OP setting with a reported success rate of $77.9 \%$ (95\% CI 75.2 to 80.4$).{ }^{182022-3033} 34$

\section{Variance in management and approach}

There was a wide variance on methodological approach within the reports. Seven studies clearly stated a conservative approach
Figure 1 PRISMA flow diagram of evidence synthesis.

\section{Electronic database \& manual search $(\mathrm{n}=\mathbf{2 8 9 8})$}

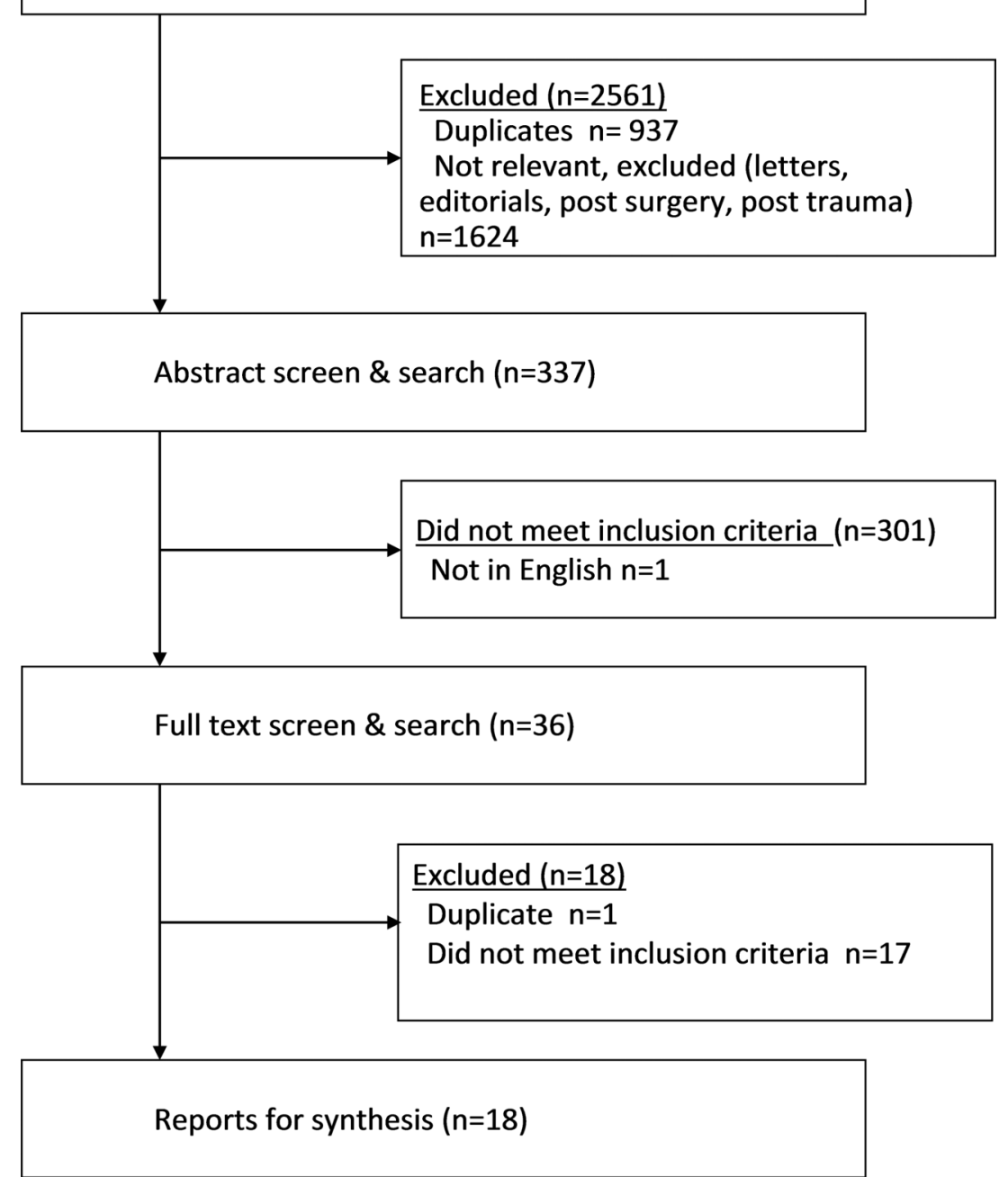


Table 1 Summary and characteristics of studies included

\begin{tabular}{|c|c|c|c|c|c|c|c|c|}
\hline Authors & Year & Study design & Outcome & $\begin{array}{l}\text { Intervention } \\
\mathrm{n}=\end{array}$ & $\begin{array}{l}\text { Pneumothorax } \\
\text { type }\end{array}$ & Exclusions & Setting & Quality \\
\hline Ho et al & 2011 & $\mathrm{RCT}$ & $\begin{array}{l}\text { Need for second } \\
\text { procedure }\end{array}$ & $\begin{array}{l}25(23 \\
\text { controls) }\end{array}$ & PSP & $\begin{array}{l}\text { Tension pneumothorax, trauma, } \\
\text { pleural effusions, SSP, bleeding } \\
\text { disorders }\end{array}$ & $\begin{array}{l}\text { Single centre. } \\
\text { Singapore }\end{array}$ & $\begin{array}{l}\text { Very } \\
\text { good }\end{array}$ \\
\hline $\begin{array}{l}\text { Roeggla } \\
\text { et al }\end{array}$ & 1996 & $\mathrm{RCT}$ & $\begin{array}{l}\text { Need for second } \\
\text { procedure }\end{array}$ & $\begin{array}{l}19(13 \\
\text { controls) }\end{array}$ & SP-not defined & None stated & $\begin{array}{l}\text { Single centre. } \\
\text { Austria }\end{array}$ & Moderate \\
\hline Vallee et al & 1988 & Prospective series & Re-expansion & 37 & PSP (19), SSP (18) & $\begin{array}{l}\text { Need for mechanical ventilation, } \\
\text { hydrothorax, tension pneumothorax }\end{array}$ & $\begin{array}{l}\text { Single centre. } \\
\text { USA }\end{array}$ & Good \\
\hline $\begin{array}{l}\text { Marquette } \\
\text { et al }\end{array}$ & 2006 & $\begin{array}{l}\text { Prospective } \\
\text { consecutive cases }\end{array}$ & Re-expansion & 41 & PSP & Previous pneumothorax & $\begin{array}{l}\text { Single centre. } \\
\text { France }\end{array}$ & Good \\
\hline $\begin{array}{l}\text { Dernevik } \\
\text { et al }\end{array}$ & 2003 & Prospective series & $\begin{array}{l}\text { Treatment as } \\
\text { outpatient }\end{array}$ & 55 & PSP (35), SSP (20) & None stated & $\begin{array}{l}\text { Single centre. } \\
\text { Sweden }\end{array}$ & Moderate \\
\hline Lai et al & 2012 & $\begin{array}{l}\text { Retrospective } \\
\text { case-note review }\end{array}$ & $\begin{array}{l}\text { Need for second } \\
\text { procedure }\end{array}$ & 55 & PSP & Tension pneumothorax & $\begin{array}{l}\text { Single centre. } \\
\text { Singapore }\end{array}$ & Poor \\
\hline Ponn et al & 1997 & $\begin{array}{l}\text { Retrospective } \\
\text { series }\end{array}$ & $\begin{array}{l}\text { Treatment as } \\
\text { outpatient }\end{array}$ & 240 & PSP (96), SSP (80) & Pleural effusion, pleural infection & $\begin{array}{l}\text { Single centre. } \\
\text { USA }\end{array}$ & Poor \\
\hline $\begin{array}{l}\text { Hassani } \\
\text { et al }\end{array}$ & 2009 & $\begin{array}{l}\text { Retrospective case } \\
\text { series }\end{array}$ & Re-expansion & 62 & PSP & $\begin{array}{l}\text { SSP, IP, postsurgery, traumatic, } \\
\text { tension pneumothorax, effusion }\end{array}$ & $\begin{array}{l}\text { Single centre. } \\
\text { Canada }\end{array}$ & Moderate \\
\hline $\begin{array}{l}\text { Campisi } \\
\text { et al }\end{array}$ & 1997 & $\begin{array}{l}\text { Retrospective case } \\
\text { series }\end{array}$ & $\begin{array}{l}\text { Treatment as } \\
\text { outpatient }\end{array}$ & 14 & PSP (13), SSP (1) & None stated & $\begin{array}{l}\text { Single centre. } \\
\text { USA }\end{array}$ & Poor \\
\hline $\begin{array}{l}\text { Cannon } \\
\text { et al }\end{array}$ & 1981 & $\begin{array}{l}\text { Retrospective } \\
\text { series }\end{array}$ & $\begin{array}{l}\text { Treatment as } \\
\text { outpatient }\end{array}$ & 41 & PSP (34), IP (7) & None stated & $\begin{array}{l}\text { Single centre. } \\
\text { USA }\end{array}$ & Poor \\
\hline $\begin{array}{l}\text { Mercier } \\
\text { et al }\end{array}$ & 1976 & Case series & $\begin{array}{l}\text { Treatment as } \\
\text { outpatient }\end{array}$ & 226 & PSP (174), SSP (52) & None stated & $\begin{array}{l}\text { Single centre. } \\
\text { Canada }\end{array}$ & Poor \\
\hline Page et al & 1975 & $\begin{array}{l}\text { Retrospective case } \\
\text { series }\end{array}$ & $\begin{array}{l}\text { Treatment as } \\
\text { outpatient }\end{array}$ & 104 & PSP & None stated & $\begin{array}{l}\text { Single centre. } \\
\text { Canada }\end{array}$ & Poor \\
\hline Conces et al & 1988 & $\begin{array}{l}\text { Retrospective case } \\
\text { series }\end{array}$ & Re-expansion & 84 & PSP (14), IP (66) & None stated & $\begin{array}{l}\text { Single centre. } \\
\text { USA }\end{array}$ & Poor \\
\hline $\begin{array}{l}\text { Bernstein } \\
\text { et al }\end{array}$ & 1973 & $\begin{array}{l}\text { Retrospective case } \\
\text { series }\end{array}$ & Re-expansion & 18 & $\mathrm{SP}-$ not defined & None stated & $\begin{array}{l}\text { Single centre. } \\
\text { UK }\end{array}$ & Poor \\
\hline $\begin{array}{l}\text { Minami } \\
\text { et al }\end{array}$ & 1992 & $\begin{array}{l}\text { Prospective case } \\
\text { series }\end{array}$ & Re-expansion & 71 & SP_not defined & IP & $\begin{array}{l}\text { Single centre. } \\
\text { Japan }\end{array}$ & Moderate \\
\hline Martin et al & 1996 & $\begin{array}{l}\text { Retrospective case } \\
\text { series }\end{array}$ & Re-expansion & 84 & $\begin{array}{l}\text { PSP (11), SSP (21), } \\
\text { IP (52) }\end{array}$ & $\begin{array}{l}\text { hydropneumothorax, tension } \\
\text { pneumothorax, need for mechanical } \\
\text { ventilation }\end{array}$ & $\begin{array}{l}\text { Single centre. } \\
\text { USA }\end{array}$ & Moderate \\
\hline Choi et al & 2007 & $\begin{array}{l}\text { Retrospective case } \\
\text { series }\end{array}$ & $\begin{array}{l}\text { Treatment as } \\
\text { outpatient }\end{array}$ & 47 & PSP (43), SSP (4) & $\begin{array}{l}\text { Trauma, hydropneumothorax, pleural } \\
\text { infection }\end{array}$ & $\begin{array}{l}\text { Single centre. } \\
\text { Korea }\end{array}$ & Moderate \\
\hline Gupta et al & 2008 & $\begin{array}{l}\text { Retrospective case } \\
\text { series }\end{array}$ & $\begin{array}{l}\text { Treatment as } \\
\text { outpatient }\end{array}$ & 191 & IP & None stated & $\begin{array}{l}\text { Single centre. } \\
\text { USA }\end{array}$ & Moderate \\
\hline
\end{tabular}

Intervention, use of a HV for treatment of a pneumothorax; IP, iatrogenic pneumothorax; PSP, primary spontaneous pneumothorax; RCT, randomised controlled trial; SP, spontaneous pneumothorax; SSP, secondary spontaneous pneumothorax.

to small PSP. ${ }^{17} 20{ }^{27-31}$ Algorithms for active treatment varied from placement of a catheter with $\mathrm{HV}$ followed by $\mathrm{NA},{ }^{22} 30$ $\mathrm{HV}$ plus underwater seal, ${ }^{28} \mathrm{HV}$ plus suction, ${ }^{25}$ or $\mathrm{HV}$ with

Table 2 Overall outcomes from all studies

\begin{tabular}{lrlr}
\hline Outcome measure: & $\mathrm{n} / \mathrm{N}=$ & $\%$ & \multicolumn{1}{c}{$95 \% \mathrm{Cl}$} \\
\hline Success with HV alone: & & & \\
$\quad$ All cases & $1060 / 1235$ & 85.8 & 83.7 to 87.7 \\
As outpatient & $761 / 977$ & 77.9 & 75.2 to 80.4 \\
PSP & $344 / 413$ & 83.3 & 79.4 to 86.6 \\
SSP & 110124 & 88.7 & 81.9 to 93.4 \\
$\quad$ latrogenic pneumothorax & $237 / 243$ & 97.5 & 94.7 to 98.9 \\
Need for surgery (all HV cases) & $119 / 1181$ & 10.1 & 8.5 to 11.9 \\
Reoccurrence (all HV cases: 6-31 & $40 / 266$ & 15.0 & 11.2 to 19.8 \\
months follow up) & & & \\
\hline
\end{tabular}

'Success' is defined as the 'use only of a HV (with intercostal catheter) to manage the pneumothorax, that is, avoidance of larger ICT and/or surgery' with all studies having variable designs and management algorithms.

HV, Heimlich valve; PSP, primary spontaneous pneumothorax; SSP, secondary

spontaneous pneumothorax. no further action. ${ }^{17} 20212731$ Several series did not discharge patients from hospital unless there had been objective improvements in CXR appearances of the pneumothorax by whatever means. $^{23} 2528293334$

The size of intercostal catheter used varied at 5.5-20 F tubes, with the older reports favouring larger tubes; all the reports in the last 10 years used catheters less than $12 \mathrm{~F}$. Anatomical placement of the tubes varied between the second intercostal space, midclavicular line and fifth intercostal space, anterior midaxillary line.

\section{Need for surgery}

All but two studies ${ }^{18} 21$ presented outcome data for patients requiring surgery for persistent pneumothorax. For all patients treated with HV, 119/1181 (10.1\%) required surgical intervention, usually for persistent air leak. Protocol and methodological approach as to the appropriate timing and indication for surgery varied widely. One study from Korea reported a remarkably high requirement for surgery of $26 / 47(55.3 \%)^{33}$ with little explanation, although the use of suction was not commented upon. 


\section{Financial}

Four studies reported healthcare economic utilisation, with data for three usable. One study ${ }^{22}$ compared the use of HV in inpatients as compared with standard inpatient ICT and reported a cost ratio of 1:3. The same study examined the cost of NA versus inpatient ICT, and reported a cost ratio of 1:7. Two studies ${ }^{27} 33$ compared the use of OP HV with inpatient ICT reporting cost ratios of 1:3.5 and 1:5.

\section{Recurrence}

Data on long-term recurrence of pneumothorax after HV treatment was presented in five studies. Reported recurrence rates varied between $11 \%$ and $24 \%$ with follow-up periods between 6 months and 31 months. ${ }^{15} 172533$ One study reported a recurrence rate after $\mathrm{HV}$ use of $7 \%$ with no follow-up period stated. $^{32}$

\section{Complications}

Serious complications were rare, and no deaths were reported as a consequence of HV treatment. Table 3 presents a summary of data on complications.

\section{DISCUSSION}

This is the first systematic review to examine the evidence for the use of $\mathrm{HV}$ in the treatment of pneumothorax. Despite nearly 40 years of reports in the literature, quality evidence to support the use of HV for pneumothorax remains sparse with just one good-quality randomised controlled trial to accompany more than a thousand other reported cases. Despite mixed methodology and a high risk of reporting bias, there is enough data to support the notion that HV might be useful in the treatment of non-traumatic pneumothorax with reasonable treatment success on varied parameters in the studies assessed. This treatment has the potential for significant improvements in the treatment of pneumothorax, pending the results of well designed and conducted comparative studies.

The use of a HV attached to a secure intercostal catheter would potentially facilitate ambulatory treatment of pneumothorax and plausibly, in selected individuals' OP-based care. Indeed this management option has been attempted in the vast majority of cases we have identified, with reported success in 761/977 (77.9\%; 95\% CI 75.2 to 80.4). Strategy varied widely as to when a patient was discharged after initial placement of the ICT and HV. Nevertheless, given the young age group, minimal comorbidity and low mortality associated with PSP, ${ }^{5}$ there is now persuasive evidence to support further research as to the usability and safety of this approach.

Table 3 Reported complications from all studies $(n=1235)$

\begin{tabular}{ll}
\hline Complication & $\mathbf{n =}$ \\
\hline Death & 0 \\
Visceral puncture/injury & 0 \\
Haemothorax (all managed conservatively) & 4 \\
Incorrect connection—-tension pneumothorax & 1 \\
Local cellulitis & 1 \\
Tube blockage with exudate & 2 \\
HV/catheter dislodged & 8 \\
Pain after insertion & 1 \\
Surgical emphysema & 4 \\
\hline HV, Heimlich valve. &
\end{tabular}

In cases where there was clear delineation between PSP and SSP, there appears to be similar success rates with the use of HV (PSP 344/413 (83.3\%; 95\% CI 79.4 to 86.6) and SSP (110/124 (88.7\%; 95\% CI 81.9 to 93.4)), although the likelihood of selection bias in SSP cases in particular is high, with more severe or sick cases likely not to be selected for this innovative treatment. IP appears to have a good success rate with a HV (reported as 97.5\%; 95\% CI 94.7 to 98.9), which again may be biased by selection, or that these patients usually improve well, anyway, as there is frequently no ongoing air leak.

\section{Complications}

In considering the case for the use of $\mathrm{HV}$ in the management of pneumothorax, it is important to consider the complications associated with their use; table 3 lists the significant complications reported from the studies. With consideration for likely marked limitations with bias and under-reporting, there are no deaths and no visceral punctures reported, with the most common problem appearing to be tube blockage or dislodgement. Despite the frequent use of larger drains in the older reports there were few reports of significant pain. These data should be compared with known complications with insertion of chest drains where more serious harm and pain is well recognised, ${ }^{8}$ with a recent British Thoracic Society pleural procedures audit from the UK stating $25 \%$ of patients reported significant pain after insertion of a chest drain for pneumothorax. ${ }^{35}$

\section{Recurrence and need for surgery}

The indications for, and timing of, surgery in the management of SP remains controversial with little evidence base to support practice, and there was a wide spectrum of timing and indications in the studies examined for this review. The rates of those deemed to require surgery in this report $(10.1 \%)$ are comparable with reports from randomised trials examining NA versus tube drainage for $\mathrm{SP}^{36-39}$ Similarly, long-term recurrence rates reported in the $\mathrm{HV}$ studies $(15.0 \%$, range $7-24 \%$ ) are also similar to those reported elsewhere in the literature (2229\%). ${ }^{36-39}$ It is important to note that the use and timing of surgery for management of SP is controversial, with Chee et al reporting on 115 patients with SP where 97\% of PSP and 79\% of SSP with persistent air leak resolved spontaneously with tube drainage alone, with no mortality in the groups. ${ }^{40}$ Current guidelines suggest consideration of surgical referral with persistent air leak, or failure of lung re-expansion, at 3-5 days after presentation. ${ }^{8}$

\section{Implications for healthcare resources}

There is little reliable data from this review to confidently state a possible healthcare economic benefit from the use of HV to avoid hospital admission, although two studies suggest a benefit in favour of HV use compared with ICT as an inpatient. ${ }^{27} 33$ In 2005/2006, hospital episode statistics report 5954 finished consultant episodes for PSP in England. ${ }^{41}$ If half the attempts at treatment with NA are successful ${ }^{8}$ this suggests that upwards of 3000 patients with PSP will be admitted for ICT each year, with a mean length of hospital stay of 5 days. ${ }^{36}{ }^{39}$ Assuming HV is successful in the treatment of pneumothorax in approximately $80 \%$ of cases, the adoption of this treatment could save nearly 12000 bed days per year in England alone. A detailed economic analysis of healthcare utilisation of possible benefits should be integral to future prospective studies. 


\section{Limitations}

Overall, the data quality for this systematic review is fairly poor, with a high risk of reporting bias and, therefore, interpretation of these results in this study should be guarded. After direct communication with the author seeking clarity with RCT design, just one report may be regarded as very good quality ${ }^{20}$ although a prospective consecutive case series of 42 patients also provides useful data, albeit with no control group. ${ }^{17}$ Both these reports present comparable outcome and safety data to the rest of the reports in this review.

\section{SUMMARY}

After 40 years of reports using HVs in the ambulatory care of SP, reliable, quality data are sparse. The use of HV in such circumstances may have benefits for patient comfort, mobility and avoidance of hospital admission, with comparable outcomes to current practice, although the current published literature cannot reliably inform this. There is an unmet need to examine the potential for ambulatory treatment of SP with high-quality RCTs required to provide reliable data on outcomes, health-related quality of life, total days hospitalised and pain scores to inform future management.

Contributors FJHB conceived the project, performed data collection, analysis, synthesis and manuscript preparation. NAM performed data collection, analysis and manuscript preparation.

Funding FJHB received funding from the Department of Health's National Institute for Health Research Comprehensive Biomedical Research Centre funding scheme (University College London Hospitals) during the conduct of this research.

Competing interests FJHB has received reimbursement for travel expenses to medical conferences from Rocket Medical, and has worked on the advisory board for CareFusion. NAM has received research funding from Novartis and CareFusion, and has worked on the advisory board for CareFusion.

Provenance and peer review Not commissioned; externally peer reviewed.

\section{REFERENCES}

1 Miller A. Spontaneous pneumothorax. In: Light R, Lee Y. Textbook of pleural diseases. 2nd edn. London: Hodder Arnold, 2008: 515-32.

2 Emerson C. Pneumothorax: a historical, clinical, and experimental study. John Hopkins Hosp Rep 1903;11:1-450.

3 Baumann M. Non-spontaneous pneumothorax. In: Light R, Lee Y. Textbook of pleural diseases. 2nd edn. London: Hodder Arnold, 2008: 533-44.

4 Melton LJ 3rd, Hepper NG, Offord KP. Incidence of spontaneous pneumothorax in Olmsted County, Minnesota: 1950 to 1974. Am Rev Respir Dis 1979;120:1379-82.

5 Gupta D, Hansell A, Nichols T, et al. Epidemiology of pneumothorax in England. Thorax 2000:55:666-71.

6 Ferraro P, Beauchamp G, Lord F, et al. Spontaneous primary and secondary pneumothorax: a 10-year study of management alternatives. Can J Surg 1994;37:197-202.

7 Noppen M, Baumann MH. Pathogenesis and treatment of primary spontaneous pneumothorax: an overview. Respiration 2003;70:431-8.

8 MacDuff A, Arnold A, Harvey J. Management of spontaneous pneumothorax: British Thoracic Society Pleural Disease Guideline 2010. Thorax 2010;65(Suppl 2):ii18-31.

9 Simpson G. Spontaneous pneumothorax: time for some fresh air. Intern Med J 2010;40:231-4.

10 Packham S, Jaiswal P. Spontaneous pneumothorax: use of aspiration and outcomes of management by respiratory and general physicians. Postgrad Med J 2003;79:345-7.

11 Medford AR, Pepperell JC. Management of spontaneous pneumothorax compared to British Thoracic Society (BTS) 2003 guidelines: a district general hospital audit. Prim Care Respir J 2007;16:291-8.

12 Baumann MH, Strange C, Heffner JE, et al. Management of spontaneous pneumothorax: an American College of Chest Physicians Delphi consensus statement. Chest 2001;119:590-602.
13 De Leyn $\mathrm{P}$, Lismonde $\mathrm{M}$, Ninane $\mathrm{V}$, et al. Guidelines Belgian Society of Pneumology. Guidelines on the management of spontaneous pneumothorax. Acta Chir Belg 2005;105:265-7.

14 Australia \& New Zealand Clinical Trials Registry. Secondary Australia \& New Zealand Clinical Trials Registry 2013. http://www.anzctr.org.au/Trial/Registration/TrialReview. aspx?ID=336270. Trial ID: ACTRN12611000184976 (accessed 28 Jan 2013).

15 Bernstein A, Waqaruddin M, Shah M. Management of spontaneous pneumothorax using a Heimlich flutter valve. Thorax 1973;28:386-9.

16 Heimlich HJ. Valve drainage of the pleural cavity. Dis Chest 1968;53:282-7.

17 Marquette $\mathrm{CH}$, Marx A, Leroy $\mathrm{S}$, et al. Simplified stepwise management of primary spontaneous pneumothorax: a pilot study. Eur Respir J 2006;27:470-6.

18 Dernevik L, Roberts D, Hamraz B, et al. Management of pneumothorax with a mini-drain in ambulatory and hospitalized patients. Scand Cardiovasc $J$ 2003:37:172-6.

19 Moher D, Liberati A, Tetzlaff J, et al. Preferred reporting items for systematic reviews and meta-analyses: the PRISMA statement. BMJ 2009;339:b2535.

20 Ho KK, Ong ME, Koh MS, et al. A randomized controlled trial comparing minichest tube and needle aspiration in outpatient management of primary spontaneous pneumothorax. Am J Emerg Med 2011;29:1152-7.

21 Roggla M, Wagner A, Brunner $C$, et al. The management of pneumothorax with the thoracic vent versus conventional intercostal tube drainage. Wien Klin Wochenschr 1996;108:330-3.

22 Vallee $\mathrm{P}$, Sullivan $\mathrm{M}$, Richardson $\mathrm{H}$, et al. Sequential treatment of a simple pneumothorax. Ann Emerg Med 1988;17:936-42.

23 Lai SM, Tee AK. Outpatient treatment of primary spontaneous pneumothorax using a small-bore chest drain with a Heimlich valve: the experience of a Singapore emergency department. Eur J Emerg Med 2012;19:400-4.

24 Ponn RB, Silverman HJ, Federico JA. Outpatient chest tube management. Ann Thorac Surg 1997;64:1437-40.

25 Hassani B, Foote J, Borgundvaag B. Outpatient management of primary spontaneous pneumothorax in the emergency department of a community hospital using a small-bore catheter and a Heimlich valve. Acad Emerg Med 2009;16:513-18.

26 Campisi P, Voitk AJ. Outpatient treatment of spontaneous pneumothorax in a community hospital using a Heimlich flutter valve: a case series. J Emerg Med 1997;15:115-19.

27 Cannon WB, Mark JB, Jamplis RW. Pneumothorax: a therapeutic update. Am J Surg 1981;142:26-9.

28 Mercier C, Page A, Verdant A, et al. Outpatient management of intercostal tube drainage in spontaneous pneumothorax. Ann Thorac Surg 1976;22:163-5.

29 Page A, Cossette R, Dontigny L, et al. Spontaneous pneumothorax: outpatient management with intercostal tube drainage. Can Med Assoc J 1975;112:707-9.

30 Conces DJ Jr., Tarver RD, Gray WC, et al. Treatment of pneumothoraces utilizing small caliber chest tubes. Chest 1988;94:55-7.

31 Minami H, Saka H, Senda K, et al. Small caliber catheter drainage for spontaneous pneumothorax. Am J Med Sci 1992;304:345-7.

32 Martin T, Fontana G, Olak J, et al. Use of pleural catheter for the management of simple pneumothorax. Chest 1996;110:1169-72.

33 Choi SH, Lee SW, Hong YS, et al. Can spontaneous pneumothorax patients be treated by ambulatory care management? Eur J Cardiothorac Surg 2007;31:491-5.

34 Gupta S, Hicks ME, Wallace MJ, et al. Outpatient management of postbiopsy pneumothorax with small-caliber chest tubes: factors affecting the need for prolonged drainage and additional interventions. Cardiovasc Intervent Radiol 2008;31:342-8.

35 Hooper C, Maskell N. British Thoracic Society national pleural procedures audit 2010. Thorax 2011;66:636-7.

36 Noppen $M$, Alexander $P$, Driesen $P$, et al. Manual aspiration versus chest tube drainage in first episodes of primary spontaneous pneumothorax: a multicenter, prospective, randomized pilot study. Am J Respir Crit Care Med 2002;165:1240-4.

37 Harvey J, Prescott RJ. Simple aspiration versus intercostal tube drainage for spontaneous pneumothorax in patients with normal lungs. British Thoracic Society Research Committee. BMJ 1994;309:1338-9.

38 Ayed AK, Chandrasekaran C, Sukumar M. Aspiration versus tube drainage in primary spontaneous pneumothorax: a randomised study. Eur Respir J 2006;27:477-82

39 Andrivet P, Djedaini K, Teboul JL, et al. Spontaneous pneumothorax. Comparison of thoracic drainage vs immediate or delayed needle aspiration. Chest 1995; 108:335-9.

40 Chee CB, Abisheganaden J, Yeo JK, et al. Persistent air-leak in spontaneous pneumothorax — clinical course and outcome. Respir Med 1998;92:757-61.

41 HESonline. http://www.hesonline.nhs.uk Secondary http://www.hesonline.nhs.uk 2012. (accessed 27 Jul 2012). 